\title{
Measurements of precipitation in Dumont d'Urville, Adélie Land, East Antarctica
}

\author{
Jacopo Grazioli ${ }^{1,2}$, Christophe Genthon ${ }^{3}$, Brice Boudevillain ${ }^{3}$, Claudio Duran-Alarcon ${ }^{3}$, Massimo Del Guasta ${ }^{4}$, \\ Jean-Baptiste Madeleine ${ }^{5,6}$, and Alexis Berne ${ }^{1}$ \\ ${ }^{1}$ Environmental Remote Sensing Laboratory (LTE), École Polytechnique Fédérale de Lausanne (EPFL), \\ Lausanne, Switzerland \\ ${ }^{2}$ MeteoSwiss, Locarno-Monti, Switzerland \\ ${ }^{3}$ Univ. Grenoble Alpes, CNRS, IGE, 38000 Grenoble, France \\ ${ }^{4}$ Istituto nazionale di Ottica, INO-CNR, Italy \\ ${ }^{5}$ Sorbonne Universités, UPMC Univ Paris 06, UMR 8539, Laboratoire de Météorologie Dynamique (IPSL), Paris, France \\ ${ }^{6}$ CNRS, UMR 8539, Laboratoire de Météorologie Dynamique (LMD), IPSL Climate Modeling Center, Paris, France
}

Correspondence to: Jacopo Grazioli (jacopo.grazioli@epfl.ch)

Received: 10 February 2017 - Discussion started: 23 February 2017

Revised: 21 May 2017 - Accepted: 9 June 2017 - Published: 4 August 2017

\begin{abstract}
The first results of a campaign of intensive observation of precipitation in Dumont d'Urville, Antarctica, are presented. Several instruments collected data from November 2015 to February 2016 or longer, including a polarimetric radar (MXPol), a Micro Rain Radar (MRR), a weighing gauge (Pluvio ${ }^{2}$ ), and a Multi-Angle Snowflake Camera (MASC). These instruments collected the first ground-based measurements of precipitation in the region of Adélie Land (Terre Adélie), including precipitation microphysics. Microphysical observations during the austral summer 2015/2016 showed that, close to the ground level, aggregates are the dominant hydrometeor type, together with small ice particles (mostly originating from blowing snow), and that riming is a recurring process. Eleven percent of the measured particles were fully developed graupel, and aggregates had a mean riming degree of about $30 \%$. Spurious precipitation in the Pluvio ${ }^{2}$ measurements in windy conditions, leading to phantom accumulations, is observed and partly removed through synergistic use of MRR data. The yearly accumulated precipitation of snow ( $300 \mathrm{~m}$ above ground), obtained by means of a local conversion relation of MRR data, trained on the Pluvio ${ }^{2}$ measurement of the summer period, is estimated to be $815 \mathrm{~mm}$ of water equivalent, with a confidence interval ranging between 739.5 and $989 \mathrm{~mm}$. Data obtained in previous research from satellite-borne radars, and the ERA-Interim reanalysis of the European Centre for Medium-
\end{abstract}

Range Weather Forecasts (ECMWF) provide lower yearly totals: $655 \mathrm{~mm}$ for ERA-Interim and $679 \mathrm{~mm}$ for the climatological data over DDU. ERA-Interim overestimates the occurrence of low-intensity precipitation events especially in summer, but it compensates for them by underestimating the snowfall amounts carried by the most intense events. Overall, this paper provides insightful examples of the added values of precipitation monitoring in Antarctica with a synergistic use of in situ and remote sensing measurements.

\section{Introduction}

The ice sheets of Antarctica contain about $90 \%$ of the world's ice and thus their evolution has potential impacts at a global scale. They condition the evolution of the sea level height (Rignot et al., 2011; DeConto and Pollard, 2016) and the radiative budget of the lower atmosphere. In this context, the quantification and prediction of the surface mass balance (SMB) of the Antarctic ice cap is a pressing scientific topic of investigation which is carried out in order to understand whether the continent is losing or gaining ice and at what rate (Vaughan et al., 1999; Lenaerts et al., 2016).

Precipitation is an important component of the SMB as it represents, together with vapor deposition, the only net input of water and ice at the continental scale (Krinner et al., 2007). 
Precipitation is unfortunately also very difficult to monitor at high latitudes. The major problems hampering classical measurement techniques in Antarctica are, in the interior, the sparsity of human installations over a very large area; the extremely low temperatures and low precipitation amounts; and on the coasts the very strong katabatic winds blowing from the interior. Additionally, the complex logistics of Antarctic installations causes further difficulties and limitations for measurements to be conducted.

Until recently, information about precipitation was obtained indirectly by analyzing moisture transports, glaciological surface-based observations (Bromwich, 1990) and reanalysis based on numerical weather prediction models (Bromwich et al., 2011). Additionally, long-running but qualitative human observation records of clouds and precipitation have been collected at some scientific stations by staff dedicated to meteorological measurements (e.g., KönigLanglo et al., 1998). Recent research proposed a climatology of precipitation over a large part of the continent (Palerme et al., 2014, 2016) by exploiting the potential of the profiling radar on board the CloudSat satellite, which is able to sample large horizontal areas but limited by the inability to measure precipitation at altitudes below a so-called "blind-range" above ground (1200 $\mathrm{m}$ above the surface for CloudSat).

In order to validate and to improve the performance of the models, and to constrain satellite-based measurements, it is necessary to establish and maintain some in situ observation sites in the medium to long term, instrumented with precipitation measurement devices that are as autonomous and accurate as possible. There is therefore the need for accurate measurements of precipitation, including at a very local scale (Frezzotti et al., 2004; Schlosser et al., 2010; Welker et al., 2014). A recent effort in this direction was the establishment of an observatory in the escarpment zone of Dronning Maud Land, East Antarctica (Gorodetskaya et al., 2015). The synergy of in situ and remote sensing measurements allowed the very first statistics of cloud and precipitation (Gorodetskaya et al., 2014, 2015) which showed that a few intense precipitation events govern the SMB in the area; measurement combinations have also been used to evaluate the quality of satellite-based precipitation products (Maahn et al., 2014) provided by CloudSat. It has been shown that the blind range of CloudSat in the area of the measurements can lead to an underestimation of precipitation amount of the order of $10 \%$ and an underestimation of the occurrence frequency of the order of $5 \%$. The installation in DML can be considered the first well-documented observatory in Antarctica to include precipitation measurements from remote sensing and in situ instruments. An earlier effort involved co-located measurements of precipitation using radar and precipitation gauges, and was conducted at the Showa ${ }^{1}$ Japanese station (Konishi et al., 1998), but very limited information about the outcome of those measurements

${ }^{1}$ Sometimes spelled "Syowa" is yet available in the literature. A more recent effort is currently taking place in the McMurdo base, in the framework of the AWARE project Witze (2016), starting from November 2015 .

In this work we present the results of an intensive observation campaign during the austral summer 2015-2016 and a first year of precipitation measurements conducted in the French base Dumont d'Urville, Adélie Land, from November 2015 to November 2016 (and still ongoing). The data were collected in the framework of the APRES3 project (Antarctic Precipitation, Remote Sensing from Surface and Space, see http://apres3.osug.fr). We provide statistics of precipitation quantity and occurrence, and we compare them with model reanalyses and with the visual observations collected by the French meteorological office (Météo France) throughout the year. The main scientific objectives of this work are to contribute to a better quantification of precipitation in Antarctica (also by evaluating the products of numerical weather models) and to underline the innovative and promising aspects of the data collected until now, which may serve as an example for long-term monitoring of precipitation in other Antarctic regions. The paper is structured as follows: Sect. 2 describes the precipitation measurements, Sect. 3 lists the most relevant results, which are discussed and put into perspective in Sect. 4 . Section 5 provides the summary and conclusions of the paper.

\section{Methods}

Here we present data collected at a coastal location of Antarctica: the station Dumont d'Urville (DDU). The base is situated in Adélie Land, $-66.6628^{\circ} \mathrm{S}, 140.0014^{\circ} \mathrm{E}$, (41 ma.s.1.), on a coastal location highlighted in Fig. 1a. This region is located at the transition between the Antarctic continent and the Southern Ocean, where the terrain, which slopes downward from the inner continent to the coast, meets the ocean.

\subsection{Climate and operational measurements}

The climate at DDU is relatively mild in terms of temperatures, with minima rarely below $-30^{\circ} \mathrm{C}$, and maxima above $0{ }^{\circ} \mathrm{C}$ in January and December, as illustrated in Fig. 1b. On the contrary, the wind regime is more extreme: in the low layer of the atmosphere the dominant winds are katabatic, coming from the inner continent, and the dominant wind origins are always between $90^{\circ}$ (east) and $180^{\circ}$ (south), as illustrated in the wind rose of Fig. 1b. Because of the intensity and persistence of the winds, which are able to reach hurricane force, Adélie Land has often been described as the windiest place on planet Earth (e.g., Wendler et al., 1997). Standard measurements of atmospheric variables (temperature, wind speed, wind direction, relative and specific humidity, atmospheric pressure) are collected regularly all year 


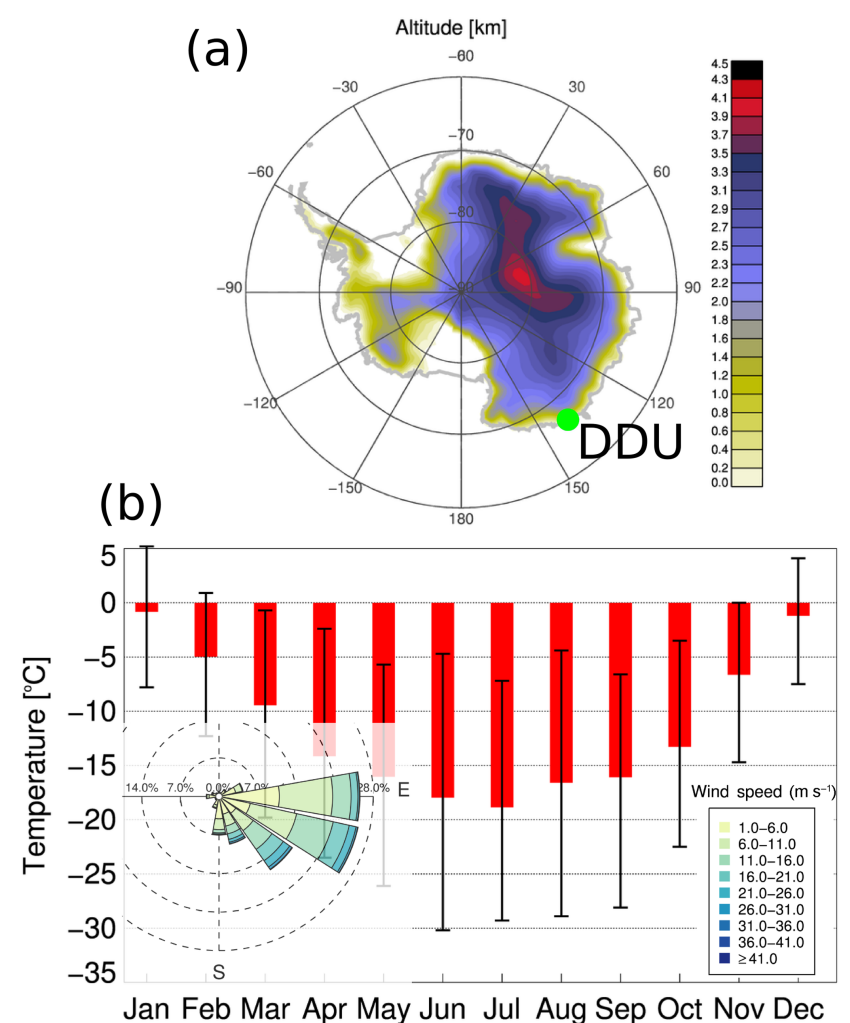

Figure 1. (a) Map of Antarctica with digital elevation model (domain south of $60^{\circ} \mathrm{S}$ ). A green filled circle locates the station Dumont d'Urville (DDU). (b) Temperature statistics in Dumont d'Urville, based on data collected at 1 min time resolution in the period 2011-2015. The red bars locate the mean value and the black error bars are used to highlight the 1 and $99 \%$ quantiles. Overlayed: wind rose (origin and intensity) statistics.

long by the French meteorological service (Météo France), and a balloon radiosounding is launched daily at 00:00 UTC. Balloon soundings have been regularly conducted since 1956 at DDU. Visual observations of cloud, precipitation, and present weather are recorded as well. It is worth noting that at this location the visual observations are the only daily in situ archive of past precipitation occurrence in DDU before the measurements described in this paper.

\subsection{APRES3 instruments}

Several instruments were deployed at DDU, starting from November 2015. The instruments were deployed as illustrated in Fig. 2, and they are listed in Table 1. A Micro Rain Radar (MRR) was installed within an existing radome and has collected uninterrupted measurements since 22 November 2015. This radar system is used to vertically profile precipitation with a resolution of $100 \mathrm{~m}$ at height levels ranging from 341 to 3141 ma.s.l. ${ }^{2}$. The processed data were col-

\footnotetext{
${ }^{2} 300 \mathrm{~m}$ is the third range gate of the MRR, where the first valid measurements are available, and $41 \mathrm{~m}$ is the altitude of DDU.
}

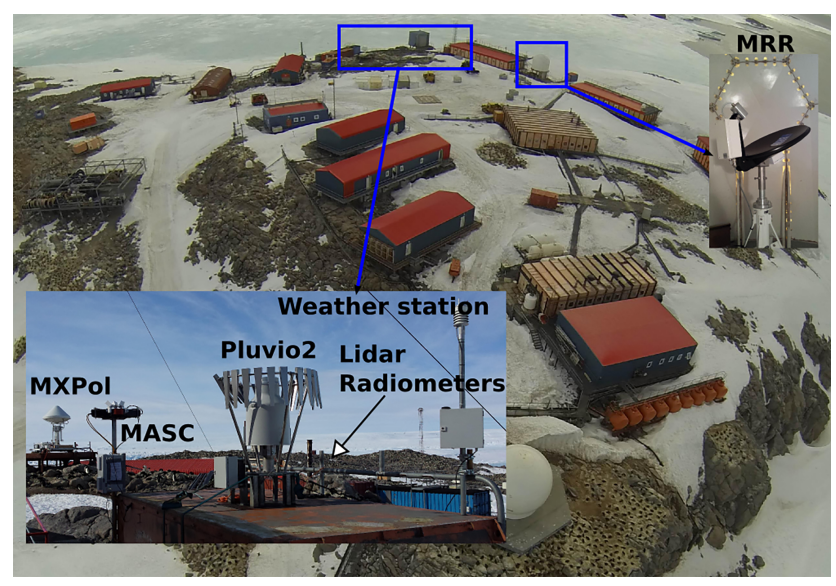

Figure 2. Main instruments deployed at DDU over the time period ranging from November 2015 to November 2016 (the MRR is, however, still collecting observations at the time of publication).

lected with a temporal resolution of $1 \mathrm{~min}$. The potential of the MRR to monitor polar regions has already been highlighted by the works of Maahn et al. (2014) and Gorodetskaya et al. (2015). The simplicity of its deployment and operation makes it an attractive tool for long-term measurements in places with complex logistics and with limited possibility of support, in the case of instrumental failures. The raw K-band reflectivity measurements collected by the MRR were first processed with the method proposed by Maahn and Kollias (2012), then converted to X-band reflectivities and in a third step to snowfall intensities. Additional information about the processing of the MRR data is provided in Sect. 2.2.1.

A second radar, named MXPol (Mobile X-band dualPolarization) collected measurements in the months of December 2015 and January 2016. This system, described in Schneebeli et al. (2013) and in Scipion et al. (2013), is a scanning dual-polarization Doppler radar. During its operation period at DDU, it was mainly collecting data at $75 \mathrm{~m}$ radial resolution and a maximum radial distance of $30 \mathrm{~km}$, mostly conducting different types of scans within a repeating scanning sequence of $5 \mathrm{~min}$ : (i) plan position indicator (PPI) scans, i.e., quasi-horizontal slices of the atmosphere, (ii) range height indicator (RHI) scans, i.e., vertical slices of the atmosphere, and (iii) static vertical profiles, such as the ones performed by the MRR.

A depolarization lidar (e.g., Del Guasta et al., 1993), deployed at a distance of about $200 \mathrm{~m}$ from MXPol, collected data in December 2015 and January 2016, as a test-bed for future long-term installation of a similar device. Lidar measurements allow for the discrimination of the phase of the tropospheric clouds and detection of the occurrence of supercooled liquid water, and they complement the observations of ground-based radars, which are often not sensitive to these particles. An example is given in Fig. 3, where the time 
Table 1. Nonexhaustive list of the instruments deployed at DDU in the framework of APRES3. Only the APRES3 instruments with a certain relevance for precipitation monitoring are listed here.

\begin{tabular}{lllll}
\hline Name & Deployment period & Instrument type & Measurement & Reference \\
\hline MRR & 21 Nov 2015-ongoing & FMCW radar profiler, 24 GHz & Clouds/precipitation & Maahn and Kollias (2012) \\
MXPol & 7 Dec 2015-31 Jan 2016 & Dual-pol Doppler radar, 9.41 GHz & Clouds/precipitation & Schneebeli et al. (2013) \\
Lidar & 15 Dec 2015-29 Jan 2016 & Depolarization lidar & Clouds/precipitation & Del Guasta et al. (1993) \\
& & & & \\
MASC & 11 Nov 2015-31 Jan 2016 & Snowflake imager & Precipitation/blowing Snow & Garrett et al. (2012) \\
Pluvio $^{2}$ & 17 Nov 2015-31 Jan 2016 & Weighing gauge & Precipitation & Colli et al. (2014) \\
Biral VPF-730 & 3 Dec 2015-25 Dec 2015 & Present weather sensor & Visibility/present weather & - \\
Vaisala Weather & 11 Nov 2015-31 Jan 2016 & Weather station & T, RH, Wind & - \\
Transmitter WXT 520 & & & & \\
\hline
\end{tabular}

a: Frequency modulation continuous wave.

b: For the rest of the time this instrument was (and is) deployed on the Antarctic continent, about $5 \mathrm{~km}$ away from DDU.

c: The co-located weather station of Météo France is providing data all year long uninterruptedly.
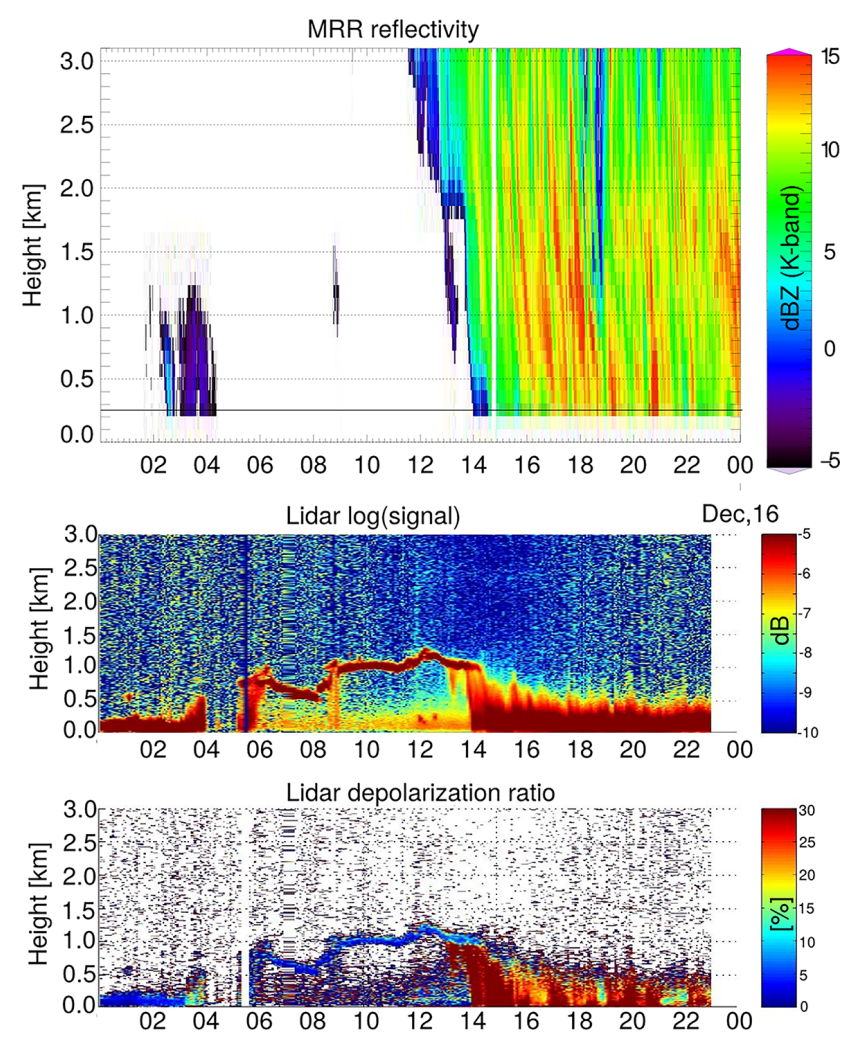

Figure 3. Example of a time series (time-height image) of MRR data and lidar data for the 15 December 2015.

series of MRR reflectivity, lidar signal and depolarization ratio are shown for the 15 December 2015. Supercooled liquid water appears in the lidar data as a layer of enhanced signal and low depolarization ratio (e.g., Del Guasta et al., 1993; Hogan et al., 2003), often when no MRR signal is visible. On the contrary, when precipitation occurs, (around 04:00 UTC, and from 14:00 to 24:00 UTC) the lidar signal gets fully attenuated in the lowest $500 \mathrm{~m}$ while the MRR is still able to sample the vertical precipitation column.
A weighing precipitation gauge (Pluvio ${ }^{2}$, manufactured by OTT) was deployed from November 2015 to January 2016. This instrument provides the liquid water equivalent of snowfall falling within its measurement area at a time resolution of $1 \mathrm{~min}$. To avoid excessive contamination of precipitation signals by blowing snow, the Pluvio ${ }^{2}$ was installed at a height of about $3 \mathrm{~m}$ above ground and its inlet was protected by a standard wind fence designed by the same manufacturer as the instrument. It must be noted that this wind shield is not sufficient to avoid the adverse effect of strong wind (frequently occurring at DDU).

Located close to the weighing gauge, a multi-angle snowflake camera (MASC) was deployed, also during the period from November 2015 to January 2016. This instrument collects high-resolution stereoscopic photographs of snowflakes in free fall, while they cross its sampling area (Garrett et al., 2012), thus providing information about snowfall microphysics and particle fall velocity. The MASC used three identical $2448 \times 2048$ pixels cameras (with common focal point) with apertures and exposure times adjusted to trade off the contrast on snowflakes photographs and motion blur effects, and a resolution of about $33 \mu \mathrm{m}$ per pixel. The cameras are triggered when a falling particle crosses two series of near-infrared sensors. A detailed description of the system and its calibration can be found in Garrett et al. (2012),and Praz et al. (2017). To complete the set of in situ measurements, a weather station (Vaisala Weather Transmitter WXT 520) was installed close to the Pluvio $^{2}$ and the MASC to sample the environmental conditions in the close proximity of their measurements, as illustrated in Fig. 2.

\subsubsection{Pre-processing of MRR data}

The MRR was co-located with MXPol for the period of the summer campaign 2015/2016 (See Table 1). The purpose of the former instrument at DDU is long-term monitoring, which involves exposure to the extremely windy winter conditions. It was decided, in order to avoid failures during the winter when no member of the scientific team is on site, to 
install the MRR inside an existing radome previously used in the base for satellite communications, as shown in Fig. 2. Although this installation ensures protection and easy access to the instrument, it adds an unknown amount of attenuation to the measurements. For this reason the co-located MXPol measurements collected during the summer period are used to map the radome-affected reflectivity data provided at $\mathrm{K}$ band (MRR) into X-band reflectivities.

The scatter plot in Fig. 4 shows the comparison of reflectivity values measured by the MRR and by MXPol for data collected during the period of co-location of the instruments. Because overall the relation between the two sets of measurements is close to linear $\left(\rho^{2} \approx 0.88\right)$, and almost equivalent to a simple offset subtraction, we can hypothesize that the eventual non-Rayleigh effects, due to centimeter-size snowflakes, were similar at the two frequencies and the following conversion has been applied to MRR data:

$Z_{\mathrm{X}}=0.99 Z_{\mathrm{K}}+6.14 \pm \epsilon$,

where $Z_{\mathrm{X}}\left(Z_{\mathrm{K}}\right)$ [dBZ] is used to indicate reflectivity at $\mathrm{X}$ (K-)band, and $\epsilon$ is the measure of uncertainty of the linear relation with respect to the scatter plot of Fig. 4 (whose standard deviation of the residuals is $1.9 \mathrm{~dB}$ ). It is worth mentioning that $Z_{\mathrm{K}}$ is originally obtained with the method of Maahn and Kollias (2012), who proposed an improved and innovative processing chain for MRR data collected in snow. Once mapped to X-band, reflectivity can be converted to snowfall rate $S$ rate by means of $Z-S$ power laws available in the literature. For example, the six relations proposed by Matrosov et al. (2009) and listed in Table 2 can be used. These relations were obtained by combining two different snowflake size distribution data sets, and three different mass-to-size relations. The error component of Eq. (1) and the large variability of the $Z-S$ relations lead to very uncertain retrievals of snowfall rate. For this reason, we optimized a local power law, by fitting its two parameters in the $Z-S$ space given by the MRR measurements at the lowest available height and the Pluvio ${ }^{2}$ measurements collected close to the ground, during the summer period 2015/2016. The parameters (intercept and exponent) of the power law are obtained by means of nonlinear least square estimation. The local relation, also listed in Table 2 , takes the form of $Z=76 S^{0.91}$. In order to mitigate the difference in sampling volume of the two instruments, it has been derived for hourly data. The $95 \%$ confidence intervals for the two parameters are 69-83 (prefactor) and 0.78-1.09 (exponent).

\subsubsection{Pre-processing of Pluvio ${ }^{2}$ data}

It has been observed that occasionally the values of equivalent water of the Pluvio ${ }^{2}$ show a "phantom" accumulation (similar to that reported by World Meteorological Organization, 2014). In such cases, no precipitation was observed by the researchers that were present on site and no precipitation signal was visible in the MRR data but the content of

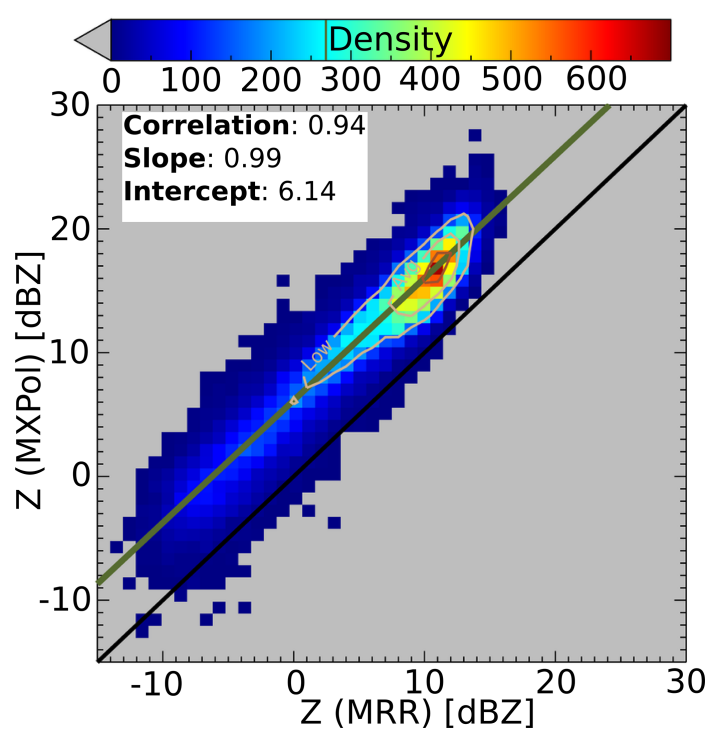

Figure 4. Scatter plot of reflectivity values at $9.41 \mathrm{GHz}$ (X-band, measured by MXPol) and at $24.3 \mathrm{GHz}$ (K-band, measured by the MRR) during the summer campaign 2015/2016. The data correspond to time steps at which both radar were profiling (PPI and RHI scans of MXPol do not contribute).

Table 2. Parameters of the six X-band conversion relations between radar reflectivity $Z$ and snowfall intensity $S\left(\mathrm{~mm} \mathrm{~h}^{-1}\right.$ ] of Matrosov et al., 2009, and the local relation, obtained using the instruments at DDU. In these relations, the radar reflectivity $(Z)$ must be used in linear units $\left[\mathrm{mm}^{6} \mathrm{~m}^{-3}\right]$. The six X-band relations originate from two different data sets (B90, ground-based, and W08, from in situ aircraft measurements), and three different mass to diameter relations, as detailed in Matrosov et al. (2009).

\begin{tabular}{ll}
\hline Relation* & Equation \\
\hline B90A (1) & $Z=67 S^{1.28}$ \\
B90B (2) & $Z=114 S^{1.39}$ \\
B90C (3) & $Z=136 S^{1.30}$ \\
W08A (4) & $Z=28 S^{1.44}$ \\
W08B (5) & $Z=36 S^{1.56}$ \\
W08C (6) & $Z=48 S^{1.45}$ \\
Local DDU & $Z=76 S^{0.91}$ \\
* Parentheses indicate the way the \\
relations were numbered in Matrosov \\
et al. (2009).
\end{tabular}

the Pluvio $^{2}$ bucket increased. In order to discard these cases, we combined the information coming from remote sensing (MRR) and in situ data (Pluvio ${ }^{2}$ ). More precisely, time steps at which no signal was recorded by the MRR at its lowest available gate (300 m a.g.l.) are considered precipitation free and any increase in the cumulative precipitation records of the Pluvio ${ }^{2}$ is thus related to external contaminations. The assumption is that precipitation is extremely unlikely to completely develop in the lowest $300 \mathrm{~m}$ of the atmosphere. An 


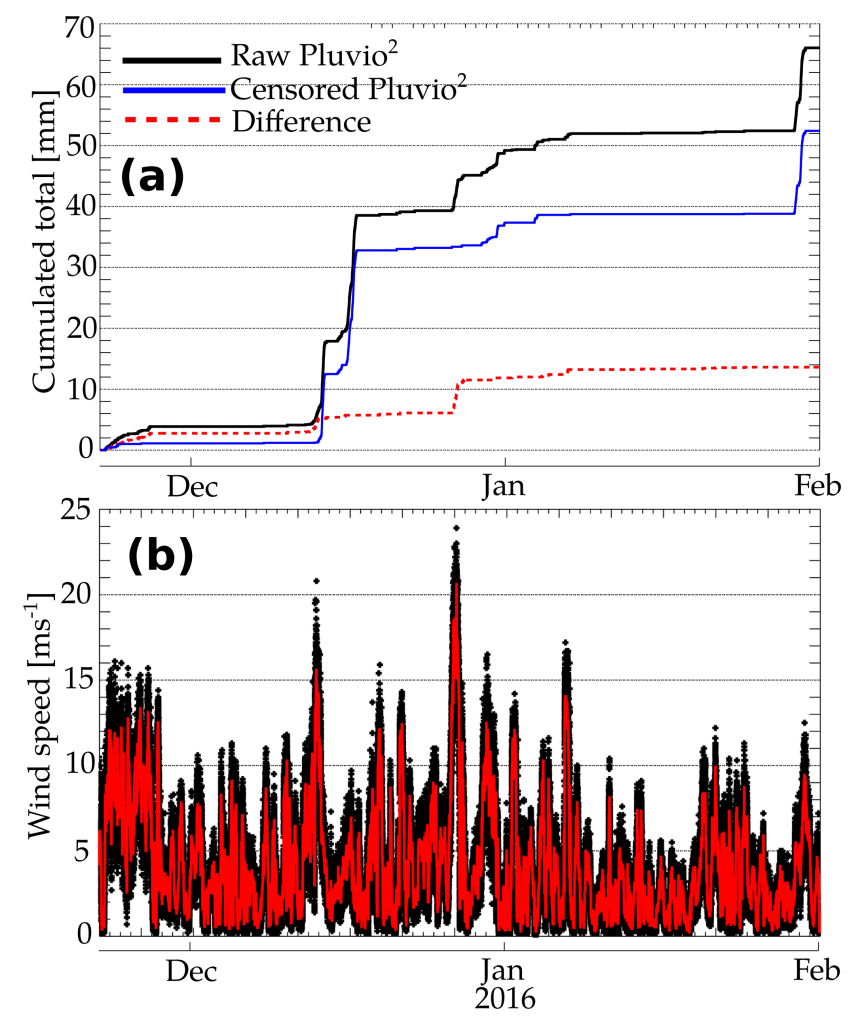

Figure 5. (a) Time series of Pluvio ${ }^{2}$ untreated data, censored data (taking the MRR measurements as occurrence indicators), and their difference. (b) Wind speed measured in the near proximity $(\leq 2 \mathrm{~m})$ of the Pluvio ${ }^{2}$ inlet, at the temporal resolution of $1 \mathrm{~min}$.

example of the behavior of this simple censoring filter can be found in Fig. 5a. From the end of October 2015 to the end of January 2016, about $14 \mathrm{~mm}$ of liquid water equivalent snowfall have been removed, corresponding to about $21 \%$ of the uncensored data.

Figure $5 \mathrm{~b}$ shows the evolution of wind speed in the near proximity of the Pluvio $^{2}$ inlet and illustrates that the most intense phantom accumulations occur when the strongest wind peaks are observed. Because the cameras of the co-located MASC were not triggered by hydrometeors during the censored time steps, we ruled out the possibility that phantom accumulation is in this case due to clear-sky blowing snow, and we hypothesize that it is caused by wind-induced vibrations of the instrument. It must be noted that this simple pretreatment cannot compensate for the contribution of snowfall mixed with blowing snow when the positive contribution of blowing snow and precipitation, and the negative contribution due to wind-induced loss of catching efficiency occur together.

\subsection{Additional data}

Due to the lack of both short- and long-term precipitation measurements, net precipitation estimates in Antarc- tica have been obtained from numerical weather prediction models (e.g., Cullather et al., 1998; Schlosser et al., 2010). Among the available model-based products, the ERAInterim global reanalysis provided by the European Centre for Medium-Range Weather Forecasts (ECMWF) is taken as a reference as it is considered to provide the best representation of precipitation variability (Bromwich et al., 2011; Palerme et al., 2014) and the best agreement with satelliteborne measurements (Behrangi et al., 2016; Palerme et al., 2016). ERA-Interim reanalysis is used here for this reason, and because of its global coverage and easy access. The analyses at 00:00 and 12:00 UTC, and forecast time steps of 6, and $12 \mathrm{~h}$ are used in the present work for the grid point which is the closest to DDU. The spatial resolution of ERA-Interim is $0.75^{\circ} \times 0.75^{\circ}$. To quantify precipitation, the model variable tp (total precipitation) is used here.

\section{Results}

\subsection{Microphysical observations during summer 2015/2016}

The period between November 2015 and January 2016 was heavily instrumented with devices that are able to provide microphysical information about precipitation; thus microphysical aspects are better documented during the summer months. While a complete investigation of the dominant microphysical processes and the small-scale dynamics of precipitation in this region is beyond the scope of this paper, it is worth investigating an important microphysical parameter: the hydrometeor type.

Hydrometeor types have been recorded near the ground level (about $2.5 \mathrm{~m}$ above ground) by the MASC instrument through the classification of individual particle pictures with the recently developed method of Praz et al. (2017), which is able to classify individual hydrometeors into six classes (and melting snow) and assign to them a continuous riming degree index ranging from 0 to 1 , with 1 corresponding to fully developed graupel. The riming degree is textural information obtained by supervised classification originating from a manually labeled training set including almost 3400 images, as detailed in Praz et al. (2017). The choice of the available classes is based on the widely used scheme of Magono and Lee (1966). Because the instruments are deployed at a height lower than 3 ma.g.l., both precipitation and blowing snow particles are recorded and classified.

A second classification method is obtained from the polarimetric data of MXPol, which can be converted into hydrometeor measurements with an hydrometeor classification algorithm (Grazioli et al., 2015). This algorithm was developed by partitioning a large number of radar observations into spatially coherent clusters by means of data mining techniques and then assigning to each cluster a dominant hydrometeor type by means of scattering simulations, interpretation of po- 

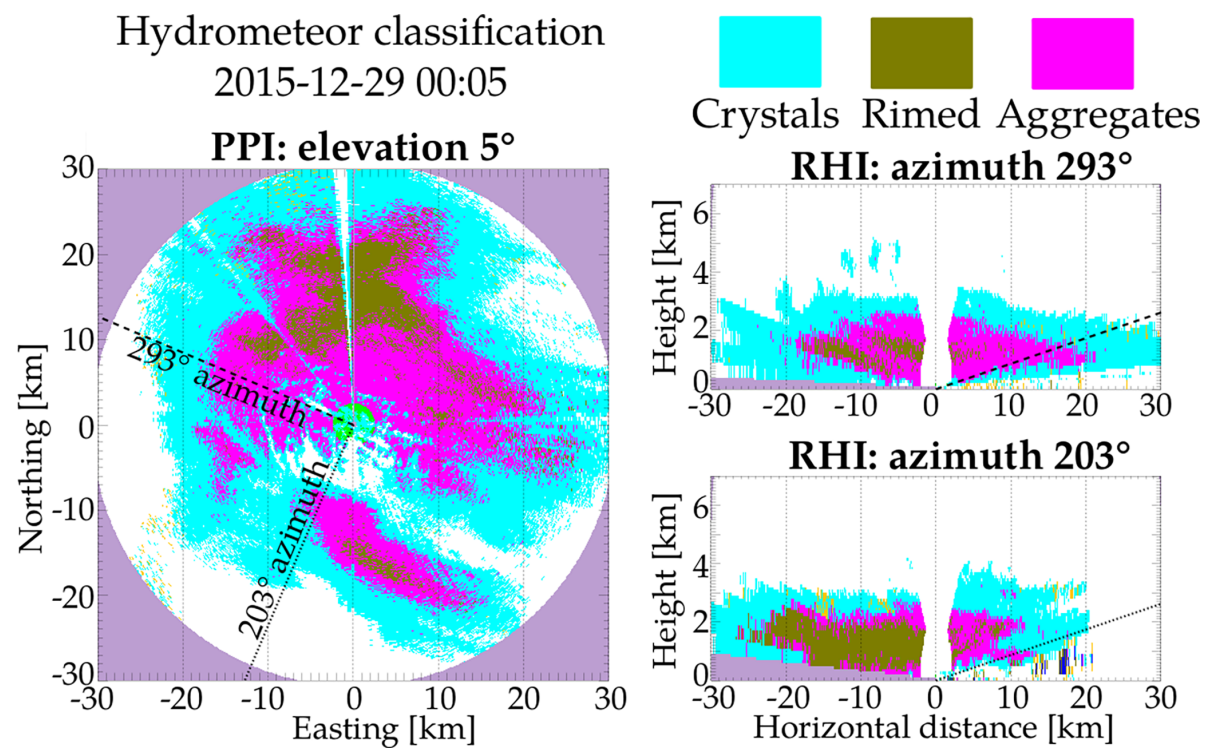

Figure 6. Example of a PPI and two RHI scans collected by MXPol on the 29 December around 00:14 UTC. The variable displayed in the image is the hydrometeor classification, obtained with the method of Grazioli et al. (2015). Noise in the classification at the lowest elevation angles is due to ground clutter. Range gates closer than $2 \mathrm{~km}$ with respect to the radar location have been censored to allow reliable polarimetric variables to be computed. Elevation angles larger than $45^{\circ}$ have been censored as well in order to limit the geometric reduction of the intensity of polarimetric signature with increasing elevation angles (Ryzhkov et al., 2005).

larimetric signatures, and comparison with in situ data. Despite the drawbacks of it being an indirect method and not being able to carry out retrievals at near-ground heights (because of ground clutter contamination in the radar data), it has the advantage of providing hydrometeor types over large domains and at different height levels, as shown in Fig. 6. Figure 6 illustrates PPI and RHI scans of the hydrometeor classification for a case where all its ice-phase hydrometeor classes are observed. This classification method discriminates pure snowfall into three categories: crystals, aggregates, and rimed particles. Figure 7 illustrates the statistical distribution of those three classes for the period of operation of MXPol, as a function of height. Below $2000 \mathrm{~m}$, the proportion of the three hydrometeor types is relatively constant with about $10 \%$ of rimed snowflakes, $40 \%$ of aggregates, and $50 \%$ of crystals. With increasing height and closeness to the cloud top, aggregates and rimed snowfall rapidly disappear while crystals constitute the dominant hydrometeor class.

The classification obtained with the MASC and the method by Praz et al. (2017) is summarized in Fig. 8. At ground level, the majority of the particles (54\%) are classified as small, indicating that hydrometeors are too small for their geometry and texture to be properly classified by the MASC. This proportion is three times higher than similar measurements collected in a wind-sheltered location in the Swiss Alps, while the proportion of the other hydrometeors is similar among the two different locations (not shown here). The occurrence of strong katabatic winds being a major dif-

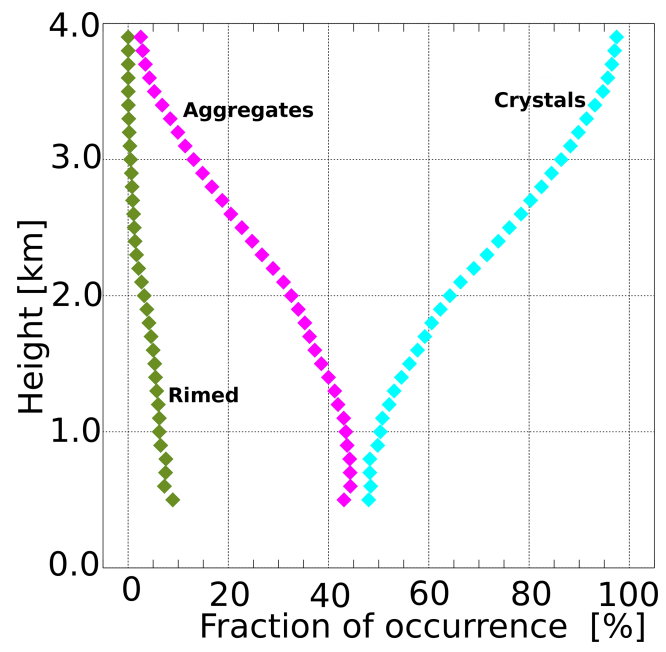

Figure 7. Fraction of occurrence of different hydrometeor types as a function of height above ground, obtained over the period of operation of MXPol, with the hydrometeor classification algorithm of Grazioli et al. (2015).

ference between the sites, it can be assumed that the large majority of these small particles observed at DDU are associated with blowing snow. During blowing snow events with strong winds (identified from visual and MRR observations on site), the number of images collected by the MASC is very large. The majority of those are classified as small particles, and this results in a large percentage of this hydrometeor type in the final statistics. Also from this classification, based on 

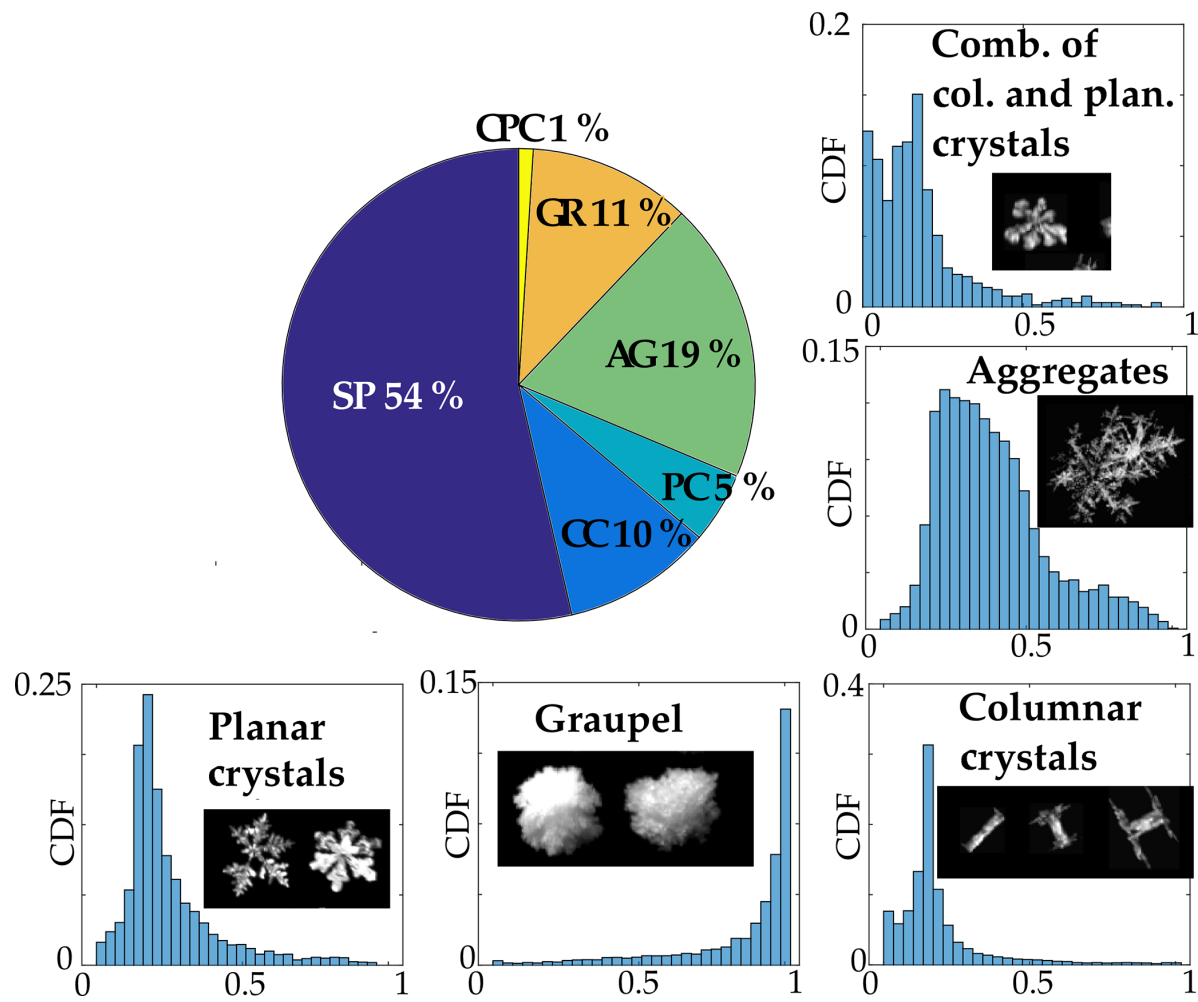

Figure 8. Pie chart of the hydrometeor types classified by the MASC instrument in the period from the 21 November 2015 to the end of January 2016. The histograms shows the distribution of a riming index, ranging from 0 (unrimed) to 1 (fully rimed), for the particles of each hydrometeor class. The riming index is undefined for small particles, i.e., particles that are too small to be identified as a particular hydrometeor class. The classes of the chart are small particles (SP), columnar crystals (CC), aggregates (AG), planar crystals (PC), graupel (GR), combination of columnar and planar crystals (CPC), as described in Praz et al. (2017).

the MASC, we observe that riming occurs. In fact, $11 \%$ of the particles are fully rimed (graupel), while all the other hydrometeor types have a riming degree ranging mostly from 0.1 to 0.5 , and are sometimes larger than 0.5 for the aggregates.

While the outcomes of the classification from MXPol and the MASC are not directly comparable because of the differences in measurement height, sampling volume, and available classes, it must be underlined that radar measurements are very sensitive to the size of the hydrometeors. Thus, a few large aggregates within a radar sampling volume will dominate and overcome the signal coming from smaller hydrometeors. This can partially explain the different proportion of aggregates observed by MXPol (about $40 \%$ at a $400 \mathrm{~m}$ height), and by the MASC (19\%). A second contribution to this difference may be the low-level mechanical breakup of the aggregates (e.g., Vardiman, 1978). A third, and very likely, contribution is the contamination of blowing snow in the MASC measurements, namely in the small particle hydrometeor class. If, assuming that most of the small particles originate from blowing snow, they are removed from the statistics, then aggregates account for $41 \%$ of the hydrom- eteors, a value much closer to the $40 \%$ obtained with the classification of MXPol.

\subsection{One year of MRR precipitation data}

The MRR instrument collected precipitation data uninterruptedly, covering the evolution of precipitation over the entire year. It therefore offers an interesting ground-based (but remotely sensed) set of data to compare with modelbased data and with available human observations. Figure 9 shows the estimates coming from the MRR and other available sources of information over a year of measurements. As expected, the agreement of the local MRR relation with the Pluvio ${ }^{2}$ is good over the summer period (DecemberJanuary), during which the relation was obtained. Also in this period the estimate of ERA-Interim provides a total cumulated precipitation within the envelope of values of the optimized $Z-S$ relation, even though the curves show some differences in precipitation occurrence. The optimized $Z-S$ relation provides estimates that are close to the $\mathrm{B} 90 \mathrm{~A}$ relation of Matrosov et al. (2009).

The months with the highest accumulated precipitation were the late fall and winter months of May and June, and 
Table 3. Monthly accumulated precipitation of snow (mm of liquid water equivalent) from the MRR, using the locally optimized $Z-S$ relation and the confidence interval of its parameters, and ERA-Interim data. The mean, minimum, and maximum snowfall of each month for ERA-Interim data from 1995 to 2015 are also shown.

\begin{tabular}{lrrrr}
\hline Month & $\begin{array}{r}\text { MRR }_{2015 / 16}^{\text {Min-Max }} \\
{[\mathrm{mm}]}\end{array}$ & $\begin{array}{r}\text { ERA }_{2015 / 16} \\
{[\mathrm{~mm}]}\end{array}$ & $\begin{array}{r}\mathrm{ERA}_{1995-2015}^{\text {Mean }} \\
{[\mathrm{mm}]}\end{array}$ & $\begin{array}{r}\mathrm{ERA}_{1995-2015}^{\text {Min-Max }} \\
{[\mathrm{mm}]}\end{array}$ \\
\hline Jan & $13.6-19.0$ & 27.6 & 52.9 & $17.7-106.4$ \\
Feb & $35.3-45.7$ & 33.4 & 44.9 & $18.8-81.5$ \\
Mar & $76.0-93.0$ & 80.9 & 55.3 & $9.9-203.3$ \\
Apr & $49.9-77.3$ & 35.4 & 51.5 & $11.8-114.3$ \\
May & $126.0-160.0$ & 113.3 & 42.7 & $5.7-108.7$ \\
Jun & $115.0-158.8$ & 80.2 & 36.5 & $4.9-81.7$ \\
Jul & $28.6-34.3$ & 36.5 & 48.6 & $2.6-96.6$ \\
Aug & $37.6-46.5$ & 27.6 & 61.8 & $16.9-113.6$ \\
Sep & $147.6-208.9$ & 113.3 & 44.2 & $4.4-75.2$ \\
Oct & $3.4-4.7$ & 8.3 & 30.9 & $0.1-117.4$ \\
Nov & $75.2-100.5$ & 72.9 & 22.5 & $1.6-59.6$ \\
Dec & $31.3-40.3$ & 25.4 & 51.4 & $17.5-131.4$ \\
\hline Total & $739.5-989.0$ & 654.8 & 543.1 & $392.8-702.5$ \\
\hline
\end{tabular}

the month of September. Seasonally ${ }^{3}$, Summer was the driest season, contributing only $11 \%$ of the yearly total, compared to values close to $30 \%$ for spring, $34 \%$ for fall, and $25 \%$ for winter (Table 3). The ERA-Interim totals of each month of the comparison period are within what could be observed in the period 1995-2015, with the exception of September, which was the snowiest since 1995 .

\subsection{Precipitation occurrence}

Long-term precipitation data records in Antarctica are often only visual observations of precipitation occurrence. For this reason, comparing precipitation occurrence measurements is a way to better understand the quality of this source of information. For the year 2015-2016, we can compare in terms of occurrence the information coming from ERAInterim, Pluvio ${ }^{2}$, MRR, and the visual observations archived by Météo France. We deal at first with occurrence at the daily scale, and we define it for the MRR and ERA-Interim as precipitation exceeding a given threshold over a given duration. A threshold of $0.07 \mathrm{~mm}$ over $6 \mathrm{~h}$ was proposed by Palerme et al. (2014), and we thus take a value of $0.28 \mathrm{mmd}^{-1}$ as a first guess. However, the choice of a unique threshold is delicate, and we also apply a minimum (maximum) threshold of $0.001 \mathrm{~mm} \mathrm{~d}^{-1}\left(1 \mathrm{~mm} \mathrm{~d}^{-1}\right)$ to cover any value that appears reasonable to assume. Figure 10 shows the number of days with precipitation recorded during each month of the measurement period.

As a past reference, the historical record of precipitation occurrences from visual daily observations for the preceding

\footnotetext{
${ }^{3}$ We refer here to the seasons of the midlatitudes of the Southern Hemisphere. Summer: December, January, and February. Fall: March, April, May. Winter: June, July, and August. Spring: September, October, and November.
}

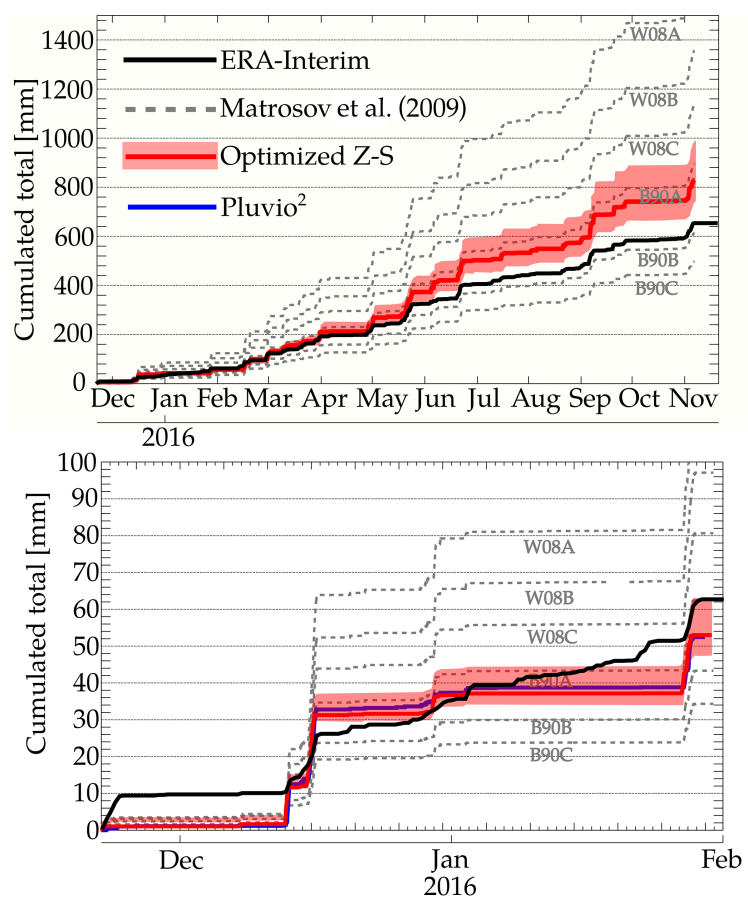

Figure 9. Time series of accumulated snowfall liquid water equivalent. The relations are obtained from Pluvio ${ }^{2}$ (in blue, for availability periods), censored from phantom precipitation, MRR (in grey the curves corresponding to the relations of Table 2, and ERAInterim data (in black). Top panel: data corresponding to the year of measurements from November 2015 to November 2016. Bottom panel: data corresponding to the summer campaign 2015/2016 from November 2015 to February 2016. 


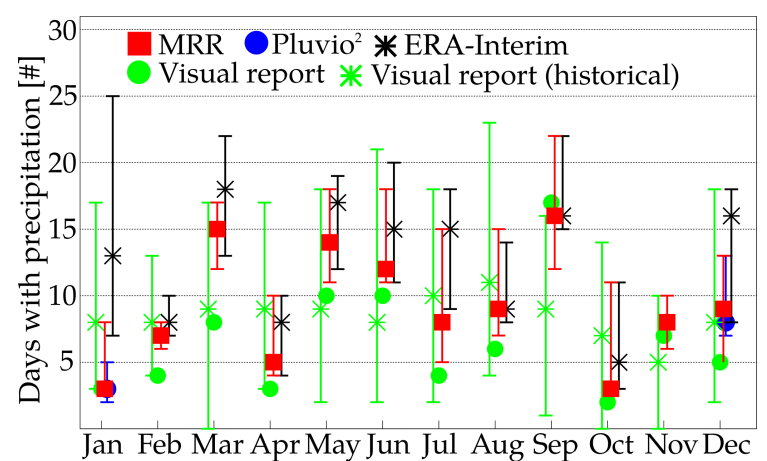

Figure 10. Precipitation occurrence at the daily scale. The error bars (where applicable) come from the use of a threshold of $0.001 \mathrm{~mm} \mathrm{~d}^{-1}$ (upper limit), and $1 \mathrm{~mm} \mathrm{~d}^{-1}$ (lower limit), while the central points are calculated with a threshold of $0.28 \mathrm{~mm} \mathrm{~d}^{-1}$ following the threshold of Palerme et al. (2014). The bars of the historical visual reports indicate instead the minimum and maximum occurrences in the period 1981-2015.

years (1981 to 2015) are also shown in green with a variability range. The year under investigation had an extremely dry January, and an extremely snowy September (in term of occurrence), while the other months are within the range of past occurrences. Overall, ERA-Interim mostly overestimates precipitation occurrence with respect to the MRR, especially in summer, while the visual observations underestimate it. For January and December, when the Pluvio ${ }^{2}$ was in operation, it is in agreement with the MRR. Given the measurement correction principle based on false detection described in Sect. 2.2.2, this implies that no misdetection is evident.

A good example of the overestimation of occurrence by ERA-Interim is shown in Fig. 9, bottom. The period between the 10 and 25 January is seen as dry by the MRR and Pluvio ${ }^{2}$, while several low-intensity precipitation events appear in the ERA-Interim time series. The overestimation of occurrence compensates for the underestimation of the most intense snowfall events, such that at the end of January the total accumulated precipitation of ERA-Interim gets close to that of the Pluvio ${ }^{2}$. As a result, the contribution of lower snowfall rates to the total accumulated snowfall is much larger for ERA-Interim, with respect to the measurements collected by the MRR and Pluvio ${ }^{2}$, and this difference is particularly pronounced in the summer period (as shown in Fig. 11).

Figure 12 shows, at a $6 \mathrm{~h}$ timescale (here we consider quantitative precipitation, thus we focus on a higher temporal resolution), the evolution of precipitation occurrence as a function of a given average precipitation intensity threshold, for the full year of observations (top panel) and for the summer campaign (bottom panel). Also here the overestimation of precipitation events by ERA-Interim is evident, especially in summer. The curves of Pluvio ${ }^{2}$ and MRR are relatively close. At the lowest thresholds the minimum inten-
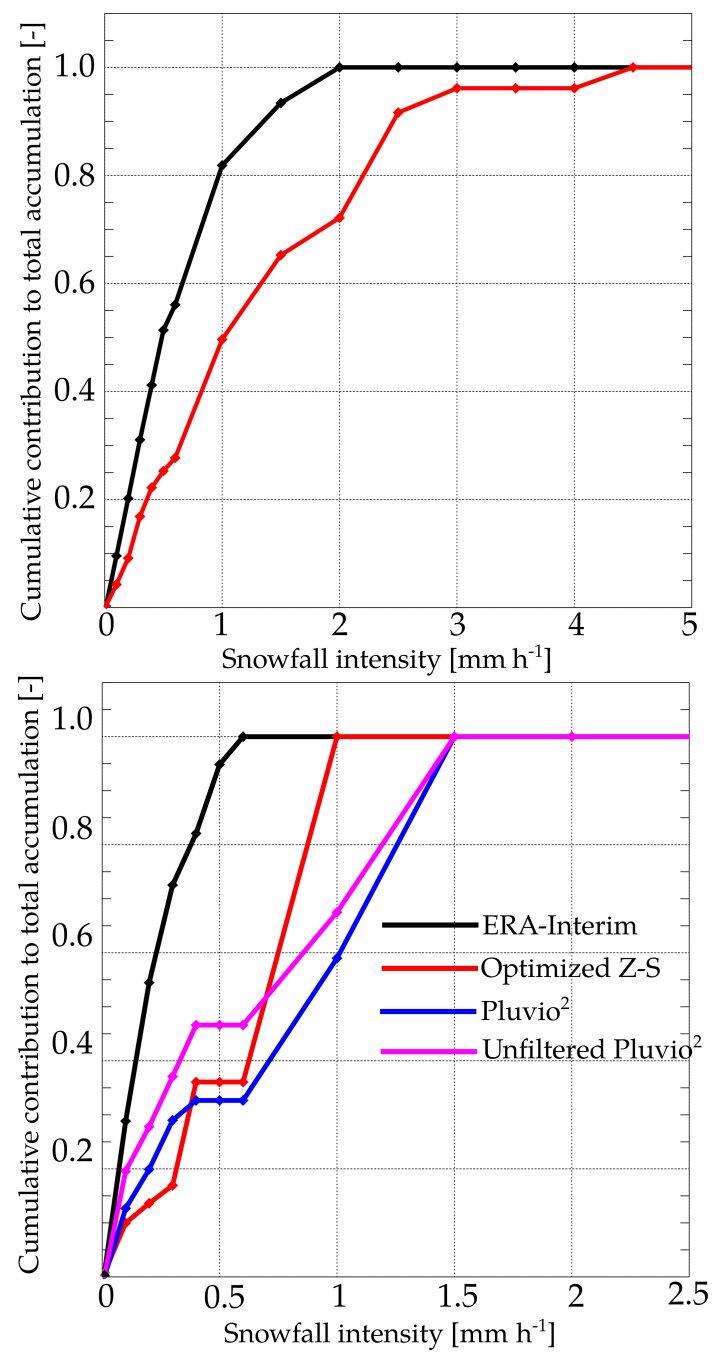

Figure 11. Cumulative contribution of increasing snowfall rates to the accumulated snowfall for the full year (top panel) and summer period (bottom panel). The timescale of snowfall intensity is also $6 \mathrm{~h}$ for MRR and Pluvio $^{2}$ data, to be consistent with the temporal resolution of ERA-Interim.

sity recordable by the Pluvio ${ }^{2}$ becomes a limitation due to the quantization effect. The black curve of ERA-Interim is above the red curve of the MRR for most of the precipitation thresholds. The two curves cross each other where the threshold is approximately $0.5 \mathrm{~mm} \mathrm{~h}^{-1}$. At $6 \mathrm{~h}$ timescale, the yearly snowfall amount is entirely associated to snowfall intensities lower than $2 \mathrm{~mm} \mathrm{~h}^{-1}$ for ERA-Interim, while intensities up to $4.4 \mathrm{~mm} \mathrm{~h}^{-1}$ have been measured with the MRR. (Fig. 11)

Visual observations provided by Météo France are not limited to precipitation, and several present weather codes are archived. At DDU, those are SYNOP codes belonging to the group $7 \mathrm{wwW} 1 \mathrm{~W} 2$. In the codes recurring at DDU, three types of phenomena are mostly documented: clouds (codes 1-3), blowing snow (codes 36-39), and snow (codes 22 and $71)$. We consider here the codes related to snow and blowing 

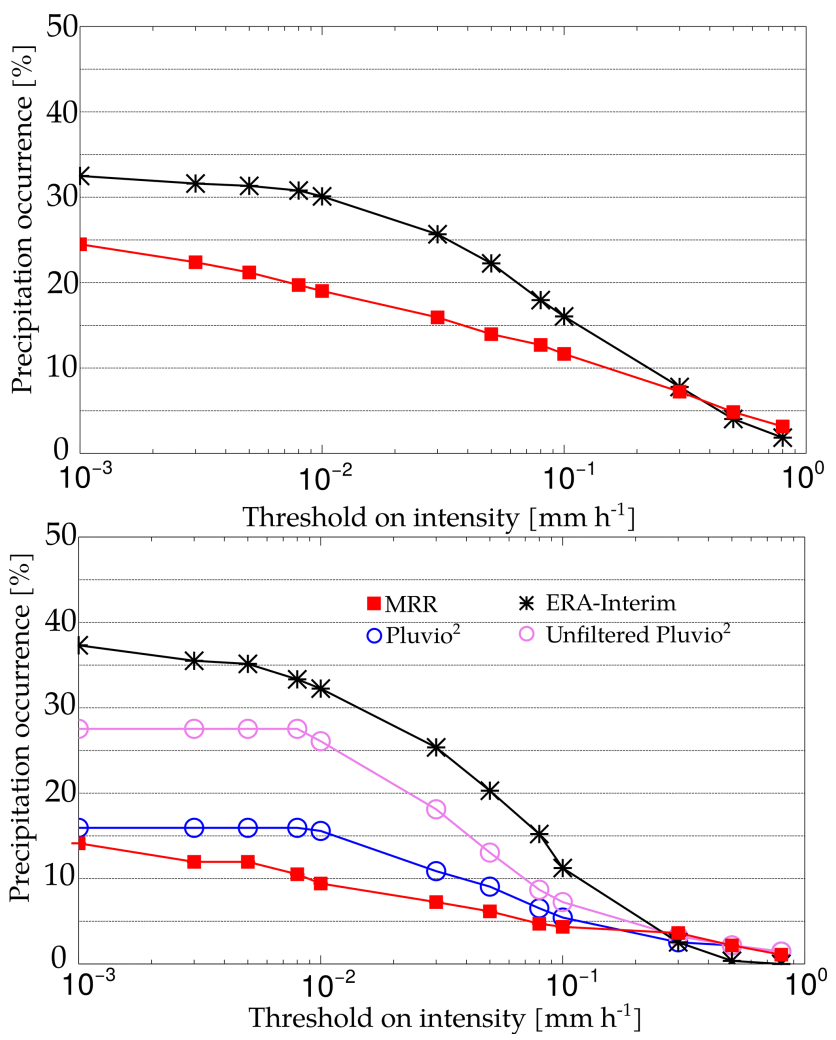

Figure 12. Precipitation occurrence as a function of the threshold on precipitation intensity for the full year (top) and summer period (bottom) respectively. The precipitation occurrence timescale is $6 \mathrm{~h}$.

Table 4. Contingency table between the occurrence of near-ground (300 m) MRR signal (columns) and visual observations of snow and blowing snow conducted by Météo France (rows). A threshold on the MRR data of $10^{-2} \mathrm{~mm} \mathrm{~h}^{-1}$ is used to discriminate between dry sky and precipitation. The elements of the contingency table are normalized to the total number of observations and sum up to $100 \%$.

\begin{tabular}{lll}
\hline & Precipitation (MRR) & Dry (MRR) \\
\hline Blowing snow & 14 & 44.4 \\
Snow & 34.9 & 6.7 \\
\hline
\end{tabular}

snow and we disregard the observations of clouds. The observations are conducted during each day, on average every $5 \mathrm{~h}$ (with higher frequency during day hours), and we compare them here with the MRR measurements. This is shown in Table 4, where the MRR observations at $300 \mathrm{~m}$ height are compared with the visual observations of snow and blowing snow.

Given the intrinsic difference between those observations, it is not possible to take one as an overall reference in the confusion matrix. However, it can be assumed that visual observations are better at reporting blowing snow, because they are conducted at the ground level, while MRR measurements at $300 \mathrm{~m}$ above ground are better at reporting snow- fall. The most interesting outcomes of this comparison are the following ones. First, there is a good correspondence between occurrence of snow according to the MRR and visual observations of snow. Second, blowing snow occurrence is not well captured by the MRR. When visual observations report blowing snow, the MRR mostly does not report any occurrence. $44.4 \%$ of the visual reports analyzed here correspond to cases where blowing snow has been observed at the ground level, but no valid signal has been recorded by the MRR. This comparison is to a certain degree dependent on the threshold used to discriminate between dry weather and precipitation in the MRR data. However, similar results have been obtained for various threshold levels (not shown here). This result, as discussed in the next section, is not unexpected because blowing snow rarely exceeds heights of $100 \mathrm{~m}$ above terrain (Palm et al., 2011).

\section{Discussion}

\subsection{Microphysical observations}

The microphysical observations, collected during the austral summer 2015-2016, and illustrated in Figs. 7 and 8 suggest that even at this location on the Antarctic coasts, riming is an important microphysical process. From radar retrievals close to the ground level, about $10 \%$ of precipitation is rimed. According to the MASC classification, $11 \%$ of the hydrometeors are fully rimed (graupel) and most of the other hydrometeor types have a degree of riming greater than 0 , in particular aggregates that tend to be larger and easier targets for riming (e.g., Houze and Medina, 2005). The presence of riming indirectly shows that mixed-phase clouds often occur and that supercooled liquid water is available in the regions of precipitation formation. This has been documented in the past at this location by Del Guasta et al. (1993), and it could be observed also in the test data collected with the depolarization lidar (see Table 1, and Fig. 3) during the summer period.

At the ground level the large majority of hydrometeors recorded by the MASC were small particles of nondiscernible habit and nondefinable riming degree (given the MASC resolution), with an occurrence three times higher than similar measurements conducted in Alpine locations. This is probably the signature of the significant contribution of blowing snow to the near-ground snow flux, which is particularly effective in recirculating small and light particles (e.g., Mann et al., 2000; Gordon et al., 2009), but it could partly be the result of the fragmentation of aggregates in the lower levels of the atmosphere, where strong katabatic winds blow.

\subsection{Blowing snow and wind effect}

The contribution of blowing snow was visible in the observations collected with the MASC, generating very large num- 
ber of small hydrometeors, and strong winds affected Pluvio ${ }^{2}$ measurements, generating phantom accumulations probably due to the vibrations of the weighing gauge. As illustrated in Fig. 5, periods with wind speeds exceeding roughly $15 \mathrm{~ms}^{-1}$ at the proximity of the inlet of the instrument generate phantom accumulations of precipitation that are removed if the MRR does not receive any signal at the same time at its lowest gate. The lowest gate of the MRR ( $300 \mathrm{~m}$ in this case) is considered to be high enough to be above the height of any wind-blown snow layer (Gordon et al., 2009; Scarchilli et al., 2010; Palm et al., 2011), which rarely exceeds $200 \mathrm{~m}$ of vertical development.

This combination of ground-based and in situ instruments should be proposed again, and maintained for at least a full year to cover all the seasons. The main limitation of the filter of Pluvio ${ }^{2}$ data is that they cannot detect cases when blowing snow occurs together with precipitation. In the case of our measurements, the total accumulated precipitation of the Pluvio $^{2}$ in the summer period drops from 66 to $52 \mathrm{~mm}$, after the censoring is performed. The removed portion is then $21 \%$ of the total raw accumulated precipitation.

Regarding blowing snow, the comparison between the occurrence of signal at the lowest MRR gate and the visual weather reports conducted by Météo France, summarized in Table 4, confirms that the current MRR configuration does not capture the occurrence of blowing snow events. Lower range gate spacing should be employed (lower than $100 \mathrm{~m}$ used in the measurements shown here) if blowing snow is of interest.

\subsection{Precipitation quantification}

The quantification of precipitation in the coastal regions of Antarctica remains a difficult task, affected by significant uncertainty. This study provides some estimates that help contextualize the information available until now. Figure 9 and the summary in Table 3 shows that MRR estimates of total accumulated precipitation at the yearly scale can diverge significantly (from 484 to $1581 \mathrm{~mm}$ ) if a range of standard $Z-S$ relations is used, while the use of a local $Z-S$ relation, calibrated in the summer season, allows for a significant reduction of this range of values (from 740 to $989 \mathrm{~mm}$ ). In this case, however, an important assumption is made; i.e., that this relation can be considered representative of the other seasons.

ERA-Interim provides a yearly estimate of $655 \mathrm{~mm}$ for the measurement period from November 2015 to November 2016, about $10 \%$ lower than the lowest estimate obtained with the local $Z-S$ relation. It must be underlined once more that the estimates provided by the MRR at DDU correspond to a minimum height of 300 ( $\pm 50 \mathrm{~m}$ above ground corresponding to a range gate spacing of $100 \mathrm{~m}$ ). This, together with the large grid of ERA-Interim, may contribute to the differences observed with the MRR. Interestingly, ERA-Interim is initially in agreement with the MRR precipitation values until March 2016, but later on it underestimates them. This may also be due to a seasonal change in snowfall type, which is no longer representative of the summer snowfall events used to build the $Z-S$ relation.

As an external reference, the mean climatological estimate proposed by Palerme et al. (2014) is of $679 \mathrm{~mm}$ over DDU (climatology obtained for the period 2006 to 2011), a value not very far from the 2015/2016 measurements.

The year of measurements $(2015 / 2016)$ was characterized by a significant interseasonal and intermonth variability. However, according to ERA-Interim records, the monthly totals are within what has been observed since 1995, with the exception of the snowy month of September 2016.

\subsection{Precipitation occurrence}

Occurrence is an interesting parameter, because it is the only precipitation-related measurement that has been collected on the DDU base for a long time. In terms of precipitation occurrence we take the MRR as a reference, because visual reports are discontinuous and affected by the limitations of visibility that can occur near the ground. Figure 12 shows that the year under investigation had some peculiarities: the month of September had the highest occurrence of precipitation since 1981, while January, February, and April all took records of the lowest monthly occurrence for the same period.

ERA-Interim generally overestimates the occurrence of precipitation, which could be caused by a sampling effect due to the much larger grid size of ERA-Interim with respect to the local MRR measurements, despite temporal integration to $6 \mathrm{~h}$ to reduce this effect. This overestimation is evident mostly in summer, in particular in December and January and it is well depicted by the time series of Fig. 9, bottom. With respect to the MRR, ERA-Interim tends to overestimate the occurrence of low-intensity events and underestimate the occurrence of high-intensity events (illustrated in Fig. 12). An optimal threshold that matches the two occurrences over the year of measurement (at $6 \mathrm{~h}$ scale) is between 0.1 and $0.5 \mathrm{~mm}$ $\mathrm{h}^{-1}$. The events of highest intensity, which can contribute to the major part of the yearly snowfall accumulation (e.g., Gorodetskaya et al., 2014, 2015) in East Antarctica, did not occur in summer. This can explain the underestimation of ERA-Interim amounts starting in March 2016 (Fig. 9).

Visual observations tend to underestimate the occurrence of precipitation, as shown in Fig. 12, but they rarely produce false alarms of precipitation, as visible in Table 4. In other words, when visual observations report precipitation, they are generally correct, but they can miss some occurrences, probably due to visibility limitations, human errors, confusion with wind-blown snow, and due to the discontinuous nature of human observations. In Fig. 12, we can observe no clear seasonality in the underestimation of occurrence. For example a large underestimation is observed both in March and in July, while in June, April, and September the occurrence is very close between MRR and visual reports. This is 
to a certain extent surprising, as a larger missed detection rate could be expected during the dark winter months, when the reduced visibility may affect human observations.

\section{Summary and conclusions}

In this paper we present unprecedented observations of precipitation collected at a coastal location of East Antarctica since October 2015. Several remote sensing and in situ instruments collected measurements during summer 2015/2016, and one (the MRR) has been operating continuously since then. These instruments have provided an insightful example of their usefulness to monitor precipitation on the Antarctic continent. It has been shown that radar data can be used to remove phantom accumulations from in situ weighing gauge observations. These accumulations, occurring in high-wind conditions and tracked down to be due mostly to vibrations, accounted for $21 \%$ of the total accumulated precipitation of the summer period. Microphysical observations at the ground level, collected by the MASC in summer, showed that the large majority of hydrometeors (54\%) were small ice particles of nondefined habit, probably resulting from blowing snow, followed by aggregates (19\%), and other hydrometeor types. Both from radar-based hydrometeor classification and from MASC measurements, it appeared that riming is a significantly active process. About $10 \%$ of the radar measurements at low-level were classified as containing rimed hydrometeors, $11 \%$ of the hydrometeors were classified as fully developed graupel ( $23 \%$ if small particles are not considered), and most of the other hydrometeors classified with the MASC showed riming degrees even larger than 0.5 . The presence of supercooled liquid water, a necessary ingredient for riming, has been reported at DDU by previous studies and was evident in the lidar measurements collected in 2015.

One year of MRR data allowed for the estimation of the total yearly precipitation, from October 2015 to October 2016, giving values ranging between 740 and $989 \mathrm{~mm}$, at least $10 \%$ larger than that provided by ERA-Interim reanalysis $(655 \mathrm{~mm})$. The MRR estimates were based on a local reflectivity-to-snowfall rate relation, obtained for summer snowfall data only. An important assumption, which will need to be verified or improved, is that we considered this relation representative for the entire year of MRR measurements. Precipitation occurrence was generally overestimated by ERA-Interim with respect to the MRR, especially in the summer period, and was underestimated by the visual reports collected by Météo France. The overestimation of occurrence by ERA-Interim could be due to its microphysical parameterization or to a spatial resolution that is very different from the one of the point measurements used as a reference. On the contrary, the underestimation of occurrence by visual reports is probably due to their discontinuous nature and the difficulties in discriminating, at the ground, pure precipitation and blowing snow. Even though they underestimate occurrence, visual observations had a very low false alarm rate on occurrence. It is worth underlining that the overestimation of occurrence by ERA-Interim partially compensates for an observed underestimation of snowfall amounts for the most significant snowfall events. This compensation, over long time periods, may lead to an overestimate of the performance of the model for individual precipitation events.

It was shown that the MRR, whose lowest measurements are about $300 \mathrm{~m}$ above ground (third gate with a $100 \mathrm{~m}$ resolution), is not able to detect blowing snow. This means that a configuration with a higher range resolution, at the expense of a lower maximum sampled height, must be used if this instrument is required to monitor blowing snow.

The measurements collected at DDU and illustrated in this paper show the potential of ground-based instruments to complement and validate satellite and numerical weather prediction model products related to precipitation. Such measurements can also provide information about the microphysical aspects of precipitation, like the dominant hydrometeor types and their degree of riming in the present case. The synergy between remote sensing and in situ instruments has the potential to improve the quantification of snowfall amounts in conditions where strong winds affect ground-based measurements, even though much remains to be done in cases when precipitation and blowing snow occur at the same time. The installation and long-term operation of a similar combination of instruments should be conducted again at DDU and at other locations in Antarctica. Efforts will be devoted to develop a better long-term constraint for radar-based snowfall estimations by means of in situ measurements of precipitation in synergy with microphysical observations and retrievals, because the relation used in this study was built on summer data only. Future work should also focus on better discriminating between snowfall and blowing snow, on the validation of satellite-based snowfall retrievals since it is of great interest to monitor the entire Antarctic continent, and in further validating ERA-Interim reanalyses and other weather and climate models.

Data availability. All the relevant observations collected in the framework of the APRES3 project will be made available as soon as possible on the website of the project (http://apres3.osug.fr), or upon direct request to the authors.

Competing interests. The authors declare that they have no conflict of interest.

Acknowledgements. The authors are thankful to Météo France, and in particular to the team of Dumont d'Urville who provided the access to their in situ measurements and observations. We thank the French Polar Institute (IPEV), in particular Gregory Tran, 
Doris Thuillier, and Patrice Godon, who allowed the APRES3 measurement campaign to take place. We thank Paul Dufay, overwinterer at DDU, who provided crucial assistance for the operation of the MRR during the winter season. The first author, Jacopo Grazioli, thanks the Swiss National Science foundation SNF for the grant 200021_163287, financing his participation to the project. The authors also acknowledge the support of the French National Research Agency (ANR) to the APRES3 project and also of CNES/TOSCA, program EECLAT. For the remote technical support provided, we want to thank Andrew Pazmany and Johnatan Leachman (Prosensing Inc., manufacturer of MXPol). Jean-Baptiste Madeleine also thanks UPMC university for financial assistance. We are thankful to Tim Raupach and Christophe Praz (EPFL LTE) for the help in proofreading and in the revision of the manuscript.

Edited by: Michiel van den Broeke

Reviewed by: two anonymous referees

\section{References}

Behrangi, A., Christensen, M., Richardson, M., Lebsock, M., Stephens, G., Huffman, G. J., Bolvin, D., Adler, R. F., Gardner, A., Lambrigtsen, B., and Fetzer, E.: Status of high-latitude precipitation estimates from observations and reanalyses, J. Geophys. Res.-Atmos., 121, 4468-4486, https://doi.org/10.1002/2015JD024546, 2016.

Bromwich, D. H.: Estimates of Antarctic Precipitation, Nature, 343, 627-629, https://doi.org/10.1038/343627a0, 1990.

Bromwich, D. H., Nicolas, J. P., and Monaghan, A. J.: An assessment of precipitation changes over Antarctica and the Southern Ocean since 1989 in contemporary global reanalyses, J. Climate, 24, 4189-4209, https://doi.org/10.1175/2011JCLI4074.1, 2011.

Colli, M., Lanza, L. G., La Barbera, P., and Chan, P. W.: Measurement accuracy of weighing and tipping-bucket rainfall intensity gauges under dynamic laboratory testing, Atmos. Res., 144, 186194, https://doi.org/10.1016/j.atmosres.2013.08.007, 2014.

Cullather, R. I., Bromwich, D. H., and Van Woert, M. L.: Spatial and temporal variability of Antarctic precipitation from atmospheric methods, J. Climate, 11, 334-367, https://doi.org/10.1175/15200442(1998)011<0334:SATVOA>2.0.CO;2, 1998.

DeConto, R. M. and Pollard, D.: Contribution of Antarctica to past and future sea-level rise, Nature, 531, 591-597, https://doi.org/10.1038/nature17145, 2016.

Del Guasta, M., Morandi, M., Stefanutti, L., Brechet, J., and Piquad, J.: One-year of cloud lidar data from DumontDurville (Antarctica). 1. General overview of geometrical and optical-properties, J. Geophys. Res., 98, 18575-18587, https://doi.org/10.1029/93JD01476, 1993.

Frezzotti, M., Pourchet, M., Flora, O., Gandolfi, S., Gay, M., Urbini, S., Vincent, C., Becagli, S., Gragnani, R., Proposito, M., Severi, M., Traversi, R., Udisti, R., and Fily, M.: New estimations of precipitation and surface sublimation in East Antarctica from snow accumulation measurements, Clim. Dynam., 23, 803-813, https://doi.org/10.1007/s00382-004-0462-5, 2004.

Garrett, T. J., Fallgatter, C., Shkurko, K., and Howlett, D.: Fall speed measurement and high-resolution multi-angle photogra- phy of hydrometeors in free fall, Atmos. Meas. Tech., 5, 26252633, https://doi.org/10.5194/amt-5-2625-2012, 2012.

Gordon, M., S. and Taylor, P. A.: Measurements of blowing snow, Part I: Particle shape, size distribution, velocity, and number flux at Churchill, Manitoba, Canada, Cold Reg. Sci. Technol., 55, 63 74, https://doi.org/10.1016/j.coldregions.2008.05.001, 2009.

Gorodetskaya, I. V., Tsukernik, M., Claes, K., Ralph, M. F., Neff, W. D., and Van Lipzig, N. P. M.: The role of atmospheric rivers in anomalous snow accumulation in East Antarctica, Geophys. Res. Lett., 41, 6199-6206, https://doi.org/10.1002/2014GL060881, 2014.

Gorodetskaya, I. V., Kneifel, S., Maahn, M., Van Tricht, K., Thiery, W., Schween, J. H., Mangold, A., Crewell, S., and Van Lipzig, N. P. M.: Cloud and precipitation properties from ground-based remote-sensing instruments in East Antarctica, The Cryosphere, 9, 285-304, https://doi.org/10.5194/tc-9-285-2015, 2015.

Grazioli, J., Tuia, D., and Berne, A.: Hydrometeor classification from polarimetric radar measurements: a clustering approach, Atmos. Meas. Tech., 8, 149-170, https://doi.org/10.5194/amt-8149-2015, 2015

Hogan, R. J., Francis, P. N., Flentje, H., Illingworth, A. J., Quante, M., and Pelon, J.: Characteristics of mixed-phase clouds. I: Lidar, radar and aircraft observations from CLARE'98, Q. J. Roy. Meteor. Soc., 129, 2089-2116, https://doi.org/10.1256/qj.01.208, 2003.

Houze, R. A. and Medina, S.: Turbulence as a mechanism for orographic precipitation enhancement, J. Atmos. Sci., 62, 35993623, 2005.

König-Langlo, G., King, J. C., and Pettré, P.: Climatology of the three coastal Antarctic stations Dumont d'Urville, Neumayer, and Halley, J. Geophys. Res., 103, 10935-10946, https://doi.org/10.1029/97JD00527, 1998.

Konishi, H., Wada, M., and Endoh, T.: Seasonal variations of cloud and precipitation at Syowa station, Antarctica, Ann. Glaciol., 27, 597-602, 1998.

Krinner, G., Magand, O., Simmonds, I., Genthon, C., and Dufresne, J. L.: Simulated Antarctic precipitation and surface mass balance at the end of the twentieth and twenty-first centuries, Clim. Dynam., 28, 215-230, https://doi.org/10.1007/s00382-006-0177-x, 2007.

Lenaerts, J. T. M., Vizcaino, M., Fyke, J., van Kampenhout, L., and van den Broeke, M. R.: Present-day and future Antarctic ice sheet climate and surface mass balance in the Community Earth System Model, Clim. Dynam., 47, 1367-1381, https://doi.org/10.1007/s00382-015-2907-4, 2016.

Maahn, M. and Kollias, P.: Improved Micro Rain Radar snow measurements using Doppler spectra post-processing, Atmos. Meas. Tech., 5, 2661-2673, https://doi.org/10.5194/amt-5-2661-2012, 2012.

Maahn, M., Burgard, C., Crewell, S., Gorodetskaya, I. V., Kneifel, S., Lhermitte, S., Van Tricht, K., and van Lipzig, N. P. M.: How does the spaceborne radar blind zone affect derived surface snowfall statistics in polar regions?, J. Geophys. Res., 119, 13604-13620, https://doi.org/10.1002/2014JD022079, 2014.

Magono, C. and Lee, C. W.: Meteorological classification of natural snow crystals, J. Fac. Sci., Hokkaido Univ., Series VII, 2, 321 335, 1966. 
Mann, G., Anderson, P., and Mobbs, S.: Profile measurements of blowing snow at Halley, Antarctica, J. Geophys. Res., 105, 24491-24508, https://doi.org/10.1029/2000JD900247, 2000.

Matrosov, S. Y., Campbell, C., Kingsmill, D., and Sukovich, E.: Assessing snowfall rates from X-band Radar reflectivity measurements, J. Atmos. Ocean. Tech., 26, 2324-2339, https://doi.org/10.1175/2009JTECHA1238.1, 2009.

Palerme, C., Kay, J. E., Genthon, C., L'Ecuyer, T., Wood, N. B., and Claud, C.: How much snow falls on the Antarctic ice sheet?, The Cryosphere, 8, 1577-1587, https://doi.org/10.5194/tc-8-15772014, 2014.

Palerme, C., Genthon, C., Claud, C., Kay, J. E., Wood, N. B., and L'Ecuyer, T.: Evaluation of current and projected Antarctic precipitation in CMIP5 models, Clim. Dynam., 48, 1-15, https://doi.org/10.1007/s00382-016-3071-1, 2016.

Palm, S. P., Yang, Y., Spinhirne, J. D., and Marshak, A.: Satellite remote sensing of blowing snow properties over Antarctica, J. Geophys. Res., 116, D16123, https://doi.org/10.1029/2011JD015828, 2011.

Praz, C., Roulet, Y.-A., and Berne, A.: Solid hydrometeor classification and riming degree estimation from pictures collected with a Multi-Angle Snowflake Camera, Atmos. Meas. Tech., 10, 13351357, https://doi.org/10.5194/amt-10-1335-2017, 2017.

Rignot, E., Velicogna, I., van den Broeke, M. R., Monaghan, A., and Lenaerts, J. T. M.: Acceleration of the contribution of the Greenland and Antarctic ice sheets to sea level rise, Geophys. Res. Lett., 38, L05503, https://doi.org/10.1029/2011GL046583, 2011.

Ryzhkov, A. V., Giangrande, S. E., Melnikov, V. M., and Schuur, T. J.: Calibration issues of dual-polarization radar measurements, J. Atmos. Ocean. Tech., 22, 1138-1155, https://doi.org/10.1175/JTECH1772.1, 2005.

Scarchilli, C., Frezzotti, M., Grigioni, P., De Silvestri, L., Agnoletto, L., and Dolci, S.: Extraordinary blowing snow transport events in East Antarctica, Clim. Dynam., 34, 1195-1206, https://doi.org/10.1007/s00382-009-0601-0, 2010.
Schlosser, E., Powers, J. G., Duda, M. G., Manning, K. W., Reijmer, C. H., and Van Den Broeke, M. R.: An extreme precipitation event in Dronning Maud Land, Antarctica: a case study with the Antarctic Mesoscale Prediction System, Phys. Rev. E, 29, 330-344, https://doi.org/10.1111/j.1751-8369.2010.00164.x, 2010.

Schneebeli, M., Dawes, N., Lehning, M., and Berne, A.: Highresolution vertical profiles of polarimetric $X$-band weather radar observables during snowfall in the Swiss Alps, J. Appl. Meteorol. Clim., 52, 378-394, https://doi.org/10.1175/JAMC-D-12-015.1, 2013.

Scipion, D., Mott, R., Lehning, M., Schneebeli, M., and Berne, A.: Seasonal small-scale spatial variability in alpine snowfall and snow accumulation, Water Resour. Res., 49, 1446-1457, https://doi.org/10.1002/wrcr.20135, 2013.

Vardiman, L.: The generation of secondary ice particles in clouds by crystal-crystal collision, J. Atmos. Sci., 35, 2168-2180, 1978.

Vaughan, D. G., L., B. J., Giovinetto, M., Russell, J., and Cooper, A. P. R.: Reassessment of the net surface mass balance in Antarctica, J. Climate, 12, 933-946, 1999.

Welker, C., Martius, O., Froidevaux, P., Reijmer, C. H., and Fischer, H.: A climatological analysis of high-precipitation events in Dronning Maud Land, Antarctica, and associated large-scale atmospheric conditions, J. Geophys. Res., 119, 11932-11954, https://doi.org/10.1002/2014JD022259, 2014.

Wendler, G., Stearns, C., Weidner, G., Dargaud, G., and Parish, T.: On the extraordinary katabatic winds of Adelie Land, J. Geophys. Res.-Atmos ., 102, 4463-4474, https://doi.org/10.1029/96JD03438, 1997.

Witze, A.: CLIMATE SCIENCE Antarctic cloud study takes off, Nature, 529, p. 12, 2016.

World Meteorological Organization: Project team and (reduced) international organizing committee for the WMO solid precipitation intercomparison experiment. Fifth Session. Final Report, WMO-No.168, World Meteorological Organization, Sodankyla, Finland, 5th edn., 2014. 